\title{
Hypotensive bradycardic events during shoulder arthroscopic surgery under interscalene brachial plexus blocks
}

\author{
Seok Young Song, and Woon Seok Roh \\ Department of Anesthesiology and Pain Medicine, School of Medicine, Catholic University of Daegu, Daegu, Korea
}

Sudden, profound hypotensive and bradycardic events (HBEs) have been reported in more than $20 \%$ of patients undergoing shoulder arthroscopy in the sitting position. Although HBEs may be associated with the adverse effects of interscalene brachial plexus block (ISBPB) in the sitting position, the underlying mechanisms responsible for HBEs during the course of shoulder surgery are not well understood. The basic mechanisms of HBEs may be associated with the underlying mechanisms responsible for vasovagal syncope, carotid sinus hypersensitivity or orthostatic syncope. In this review, we discussed the possible mechanisms of HBEs during shoulder arthroscopic surgery, in the sitting position, under ISBPB. In particular, we focused on the relationship between HBEs and various types of syncopal reactions, the relationship between HBEs and the Bezold-Jarisch reflex, and the new contributing factors for the occurrence of HBEs, such as stellate ganglion block or the intraoperative administration of intravenous fentanyl. (Korean J Anesthesiol 2012; 62: 209-219)

Key Words: Arthroscopy, Bradycardia, Hypotension, Shoulder, Syncope.

\section{Introduction}

Shoulder arthroscopy can be performed with the patient in either the lateral decubitus or the sitting position. Although surgeon have a preference for patient positioning, the sitting position has several advantages including the ease of setup, excellent intraarticular visualization for all types of arthroscopic shoulder procedures, less intraoperative blood loss, a lower incidence of traction neuropathy, and ease of conversion to the open approach if needed [1,2]. In addition, positioning during shoulder arthroscopy may affect the type of anesthesia used. Surgeons who prefer the sitting position cite the ability to use general or interscalene brachial plexus block (ISBPB) as an advantage. ISBPB is possible for patients in the sitting position; however, it is poorly tolerated in patients in the lateral decubitus position.

ISBPB provides effective anesthesia for most types of shoulder surgeries, including arthroplasty and fracture fixation. When administered by an anesthesiologist committed to and skilled in the technique, the block has an excellent rate of success and is associated with a relatively low complication rate [3]. Recently, modified applications of ISBPB, such as indwelling perineural catheters for continuous ISBPB, have revolutionized the practice of acute pain management for shoulder surgery

Received: January 31, 2012. Revised: February 29, 2012. Accepted: March 1, 2012.

Corresponding author: Woon Seok Roh, M.D., Ph.D., Department of Anesthesiology and Pain Medicine, School of Medicine, Catholic University of Daegu, 3056-6, Daemyung 4-dong, Nam-gu, Daegu 705-718, Korea. Tel: 82-53-650-4504, Fax: 82-53-650-4517, E-mail: usno@cu.ac.kr (c) This is an open-access article distributed under the terms of the Creative Commons Attribution Non-Commercial License (http:// creativecommons.org/licenses/by-nc/3.0/), which permits unrestricted non-commercial use, distribution, and reproduction in any medium, provided the original work is properly cited. 
in the postoperative period [4]. In fact, ISBPB has several advantages for patients undergoing shoulder surgery: excellent anesthesia, reduction in both intraoperative and postoperative doses of opiates, delay in the onset of postoperative pain, a shortened postanesthesia stay, and increased patient satisfaction [3-5].

One of the major disadvantages of the sitting position is cardiovascular instability during the shoulder procedure [6]. Sudden, profound hypotensive and bradycardic events (HBEs) have been reported in more than $20 \%$ of patients undergoing shoulder arthroscopy in the sitting position. Although HBEs may be associated with the adverse effects of ISBPB in the sitting position, the underlying mechanisms responsible for HBEs during the course of shoulder surgery are not well understood. The pathophysiology may be more complex than expected, and HBEs can be related to the various types of syncopal reactions. Recently, several reports have demonstrated that there are other possible mechanisms or new contributing factors for the occurrence of HBEs.

In this review, we will discuss the possible mechanisms of HBEs during shoulder arthroscopic surgery in the sitting position under ISBPB: (i) incidence and clinical manifestation of HBEs; (ii) relationship between HBEs and various types of syncopal reactions; (iii) relationship between HBEs and the Bezold-Jarisch reflex; (iv) new contributing factors for HBEs, including stellate ganglion block (SGB) in sitting position and perioperative administration of intravenous fentanyl; and (v) prevention and treatment of HBEs during shoulder surgery.

\section{Incidence and Clinical Manifestation of HBEs}

These transient but profound hypotensive and/or bradycardic events have been reported in patients undergoing shoulder surgery in a sitting position under an isolated ISBPB. Onset time of HBEs is approximately $40-80 \mathrm{~min}$ after the placement of ISBPB $[7,8]$ or $25-45 \mathrm{~min}$ from the sitting position [8]. Cardiovascular responses from HBEs include three types:

Table 1. The Incidences of HBEs

\begin{tabular}{lccc}
\hline \multicolumn{1}{c}{ Study (year) } & $\begin{array}{c}\text { Sample } \\
\text { size }\end{array}$ & $\begin{array}{c}\text { Study } \\
\text { design }\end{array}$ & $\begin{array}{c}\text { Incidence } \\
\text { rate (\%) }\end{array}$ \\
\hline Ward (1974) [11] & 34 & $\mathrm{P}$ & 21 \\
Wildsmith et al. (1977) [12] & 40 & $\mathrm{P}$ & 5 \\
Vester-Andersen et al. (1981) [13] & 100 & $\mathrm{P}$ & 12 \\
D'Alessio et al. (1995) [14] & 103 & $\mathrm{R}$ & 16 \\
D'Alessio et al. (1995) [7] & 116 & $\mathrm{R}$ & 17 \\
Liguori et al. (1998) [9] & 150 & $\mathrm{R}$ & 28 \\
Kahn and Hargett (1999) [15] & 150 & $\mathrm{R}$ & 13 \\
Seo et al. (2010) [10] & 63 & $\mathrm{P}$ & 21
\end{tabular}

$\mathrm{P}$ : prospective study, $\mathrm{R}$ : retrospective study. a mixed, bradycardic and a hypotensive type. Sia et al. [8] reported that 14 of 22 patients who had HBEs had both bradycardia and hypotension, 7 had only bradycardia and 1 had only hypotension. In the literature, HBEs have been defined as a decrease in heart rate, of at least 30 beats/min within a 5 -minute interval, any heart rate less than 50 beats $/ \mathrm{min}$, and/ or a decrease in systolic blood pressure of more than $30 \mathrm{mmHg}$ within a 5-minute interval or any systolic pressure below 90 $\mathrm{mmHg}$ [8-10]. Using this definition or criteria, the reported incidence of HBEs is $13-28 \%$ during a shoulder procedure using an isolated ISBPB [7,9-15] (Table 1). In most HBEs, these appear to be transient and isolated events occurring without the subsequent complications such as brain hypoperfusion injury, but there are a few cases reported where severe forms of HBEs have occurred, including asystolic cardiac arrest $[7,16]$. Therefore, the high incidence and potential for catastrophic complications should be considered when shoulder arthroscopic surgery is performed in the sitting position after isolated ISBPB.

\section{Relationships between HBEs and Syncopal Reactions}

The basic mechanisms of HBEs may be associated with the underlying mechanisms responsible for vasovagal syncope, carotid sinis hypersensitivity (CSH) and orthostatic syncope [17]. HBEs and various syncopal reactions may have a similar triggering mechanism and use the same efferent limb of the reflex. On the other hand, it is also possible that HBEs occur from cardiac syncope or cerebrovascular syncope. However, these types of syncopal reactions can be diagnosed preoperatively and eliminated with an electrophysiological study: conversion reaction, seizure disorders, transient ischemic attack, subclavian steal syndrome, drug-induced syncope, aortic stenosis, pulmonary hypertension, hypertrophic cardiomyopathy, and arrhythmias (sick sinus syndrome, symptomatic supraventricular tachycardia, second or thirddegree atrioventricular block, and ventricular tachycardia of more than five beats) [18]. Therefore, it is a reasonable assumption that HBEs during shoulder surgery can be associated with classical vasovagal reflex syncope, $\mathrm{CSH}$ or orthostatic syncope.

\section{Classical vasovagal reflex syncope}

It is appropriate to consider the pathophysiology of HBEs associated with vasovagal syncope in terms of afferent and efferent limbs of the reflex, the processing of the signals by the central nerve system, and finally, the role of feedback systems (Fig. 1). However, very little is known about the 
Upright posture

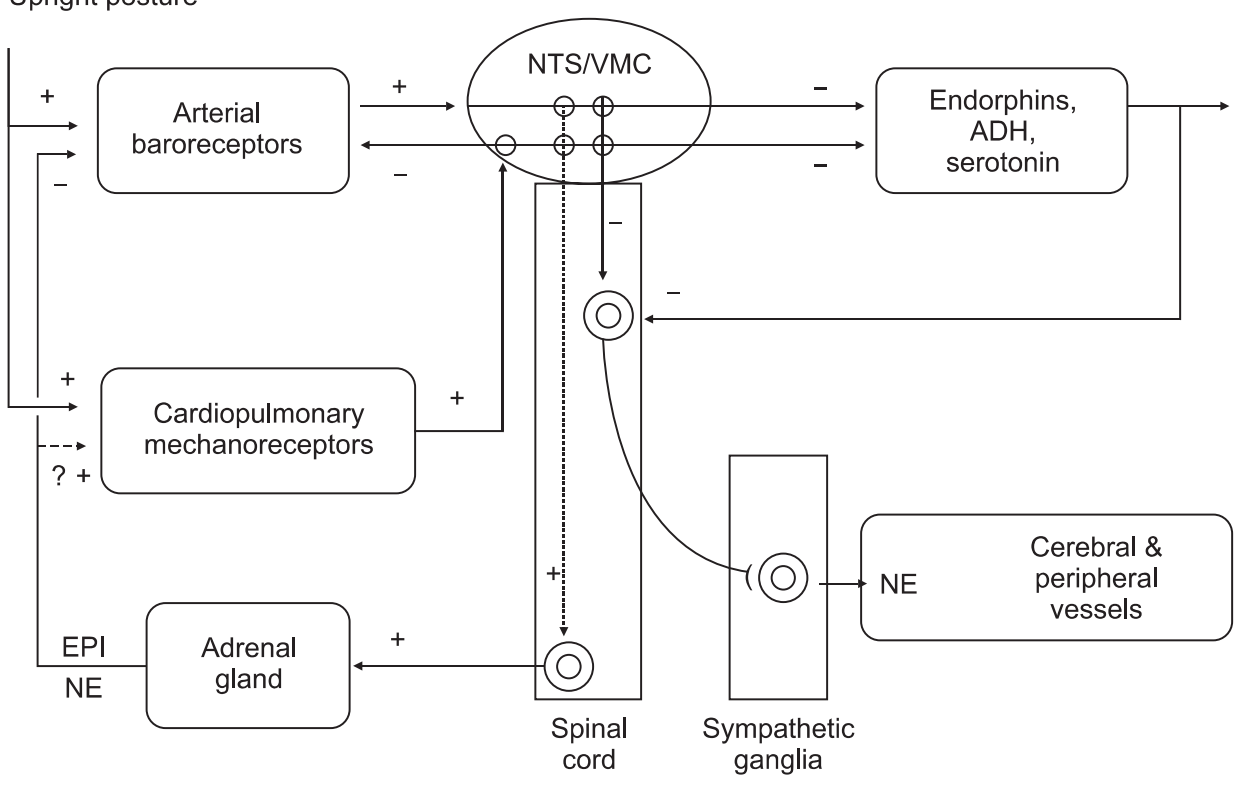

Fig. 1. This schematic picture shows that the pathophysiology of HBEs associated with vasovagal syncope in terms of afferent and efferent limbs of the reflex, the processing of the signals by the central nervous system (CNS), and finally, the role of feedback systems. $\mathrm{ADH}$ : vasopressin, $\mathrm{EPI}$ : epinephrine, $\mathrm{NE}$ : norepinephrine, NTS: nucleus tractus solitaries, VMC: vasomotor center (From Benditt et al. [19] with permission).

Table 2. Modified VASIS Classification [17]

\begin{tabular}{|c|c|c|}
\hline Class & Description & Definition \\
\hline I & Mixed & $\begin{array}{l}\text { Decrease in heart rate }>10 \% \text {, minimal heart rate }>40 \mathrm{bpm} \text { or less than } 40 \mathrm{bpm} \text { for less } \\
\text { than } 10 \text { sec with or without asystole of less than } 3 \mathrm{sec} \text {. } \\
\text { Blood pressure falls before heart rate. }\end{array}$ \\
\hline IIa & Cardioinhibitory without asystole & $\begin{array}{l}\text { Minimal heart rate }<40 \mathrm{bpm} \text { for }>10 \mathrm{sec} \text {, but asystole of more than } 3 \mathrm{sec} \text { does not occur. } \\
\text { Blood pressure falls before heart rate. }\end{array}$ \\
\hline IIb & Cardioinhibitory with asystole & $\begin{array}{l}\text { Asystole occurs for more than } 3 \text { sec. } \\
\text { Heart rate coincides with or precedes blood pressure fall. }\end{array}$ \\
\hline III & Vasodepressor & Decrease in heart rate $<10 \%$ of maximal heart rate. \\
\hline
\end{tabular}

VASIS: vasovagal syncope international study.

afferent part of the vasovagal reflex. Whereas the efferent part of the reflex is quite clear, hypotension and bradycardia are due to inhibition of the sympathetic system and to activation of the parasympathetic system, respectively. The triggers of abnormal neural reflexes are 1) fear of bodily injury; 2) painful or noxious stimuli; 3 ) venipuncture; 4) prolonged standing; 5) heat exposure; 6) exertion; and 7) coughing, swallowing or straining. Most vasovagal episodes seem to be associated with a number of different peripheral receptors. It is thought that the afferent neural signals are derived from organ receptors, which respond to mechanical or chemical stimuli. For example, cardiac mechanoreceptors alone were thought to be the important trigger sites in most cases of vasovagal syncope. In any event, the afferent neural signals associated with triggering vasovagal syncope ultimately converge on the nucleus tractus solitarius in the medulla as well as the hypothalamus. The former is closely related to the nuclei of the vagus nerve and the vasomotor center in the reticular formation, from which efferent neural activity is expected to initiate an appropriate circulatory response to any detected triggers [19]. Generally, three responses in vasovagal syncope are observed: 1) a mixed response with features of both cardioinhibitory and vasodepressor, 2) cardioinhibitory or 3) vasodepressor (Table 2). Among these responses, the cardioinhibitory response results from increased parasympathetic tone and may be manifested by any or all of the following ECG findings: 1) sinus bradycardia, 2) PR interval prolongation, and 3) advanced atrioventricular block.

Because HBEs are frequently observed in awake conditions under isolated ISBPB, all of the above-mentioned triggering stimuli could act as afferent neural signals of the vasovagal reflex arc in the patient undergoing shoulder surgery. Moreover, several investigators have suggested that underlying mechanisms for the occurrence of HBEs are the activation of the cardioinhibitory mechanoreceptor or the Bezold-Jarisch reflex $[7,20]$. Detailed discussions on the Bezold-Jarisch reflex are provided below. 


\section{$\mathrm{CSH}$}

Carotid sinus syndrome or CSH is an unusual type of vasovagal syncope. It rarely occurs in adults under 50 years, increases in prevalence with advancing age and in close relationship with accidental mechanical manipulation of the carotid sinuses, and can be reproduced by carotid sinus massage (CSM) [21]. This response is due to hypersensitivity of the afferent or efferent limbs of the carotid sinus reflex arc, resulting in vagal activation and/or sympathetic inhibition, which lead to bradycardia and/or vasodilation. $\mathrm{CSH}$ is diagnosed when CSM elicits $>3$ s asystole (cardioinhibitory type), a fall in SBP (systolic blood pressure) of $>50 \mathrm{mmHg}$ (vasodepressor type) or both (mixed type) [22]. In CSH, afferent neural signals arise from "peripheral" carotid artery baroreceptors. Debate has often centered on whether the peripheral receptor is indeed "hypersensitive" or whether the fault lies centrally in the manner in which the afferent signals are processed [19]. The latter argument has been supported by the findings of Tea et al. [23]. These investigators have suggested that the electromyographic analysis of the sternocleidomastoid (SCM) muscle differed significantly between the groups. Thirteen patients (76\%) had pathological responses in the carotid sinus syndrome group compared with only $4(23.5 \%)$ in the control group. The baroreceptors in the carotid sinus are considered to be stretch receptors that respond to deformation of the vessel wall in any direction [24]. During neck movements, mild stretches of both carotid receptors and SCM tension receptors occur.
Therefore, it is a reasonable hypothesis that proprioceptive sensitivity of the SCM could provide important information on the mechanical origin of the baroreceptor stretching during neck movement and could modulate information coming from the carotid baroreceptors. Thus, SCM proprioceptive information could produce a strong inhibitory effect on the baroreflex arc, according to the concept of a central gating of the baroreflex as developed for cardiorespiratory interactions (Fig. 2). Therefore, these observations suggest that chronic loss of innervation of the SCM is strong evidence for a peripheral origin of $\mathrm{CSH}$, with the result being an increased sensitivity of the baroreflex arc. In regard to the occurrence of HBEs during shoulder surgery, there are two possible hypotheses. The first is that HBEs occur in the prerequisite condition of $\mathrm{CSH}$ as mentioned above. In fact, ISBPB can block spinal nerves (C2C4) to SCM muscles and inhibit the transmission of SCM proprioceptive information. Consequently, acute loss of innervations of the SCM may be related to the hypersensitivity of the baroreflex arc. The second possible hypothesis is that direct manipulation of the carotid sinus, during the shoulder surgery, produces HBEs. An ultrasonography study showed that there is considerable variation in the carotid artery anatomy in young subjects [25]. Location of the right and left carotid sinus bifurcation was measured from the gonion of the mandible ( $\mathrm{n}$ = 95) and determined by Doppler ultrasound. Location of the right bifurcation was $3.2 \mathrm{~cm}$ (median $3.0 \mathrm{~cm}$, range $0-6.5 \mathrm{~cm}$ ), and the left bifurcation was $3.6 \mathrm{~cm}$ (median $3.5 \mathrm{~cm}$, range $0-7.5$ $\mathrm{cm}$ ) below the angle of the mandible. Therefore, large amounts
A

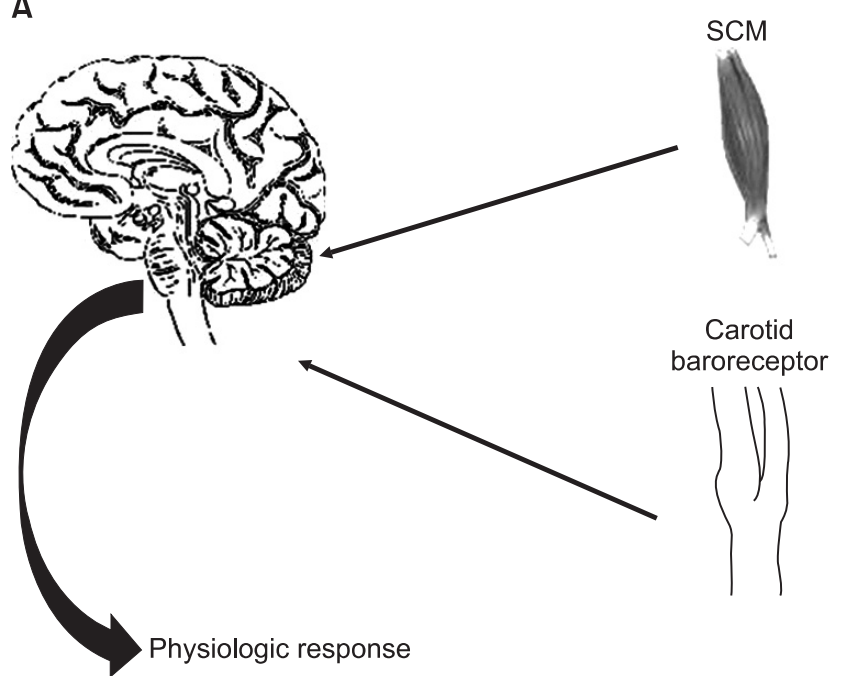

B

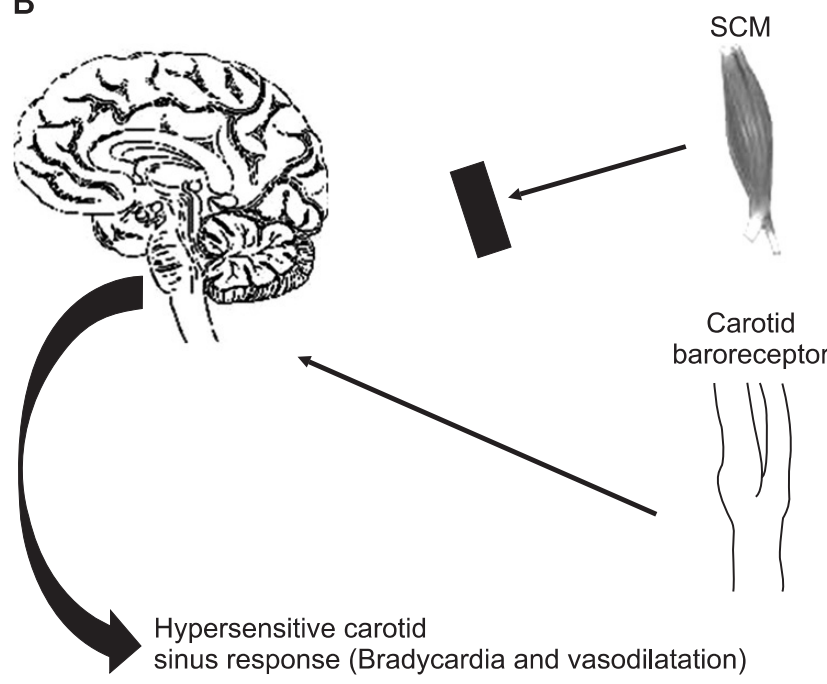

Fig. 2. This picture indicates the current concepts about the mechanism of the carotid sinus hypersensitivity. The concordent afferent signals from both the carotid sinus and the sternocleidomastoid muscles (SCM) confirm neck movement physiologically. (A) deafferentation of the SCM results in discordance of afferent signals when the neck moves. (B) SCM proprioceptive information could produce a strong inhibitory effect on the baroreflex arc, according to the concept of a central gating of the baroreflex as developed for cardiorespiratory interactions (From Benditt et al. [19] with permission). 
of local anesthetics in the ISBPB, which produce neck swelling, and frequent neck turning and arm traction during shoulder procedures, could be the triggering factors to produce direct mechanical stimulation of the carotid sinus. A few cases of asystolic cardiac arrest, during positional changes from supine to sitting in shoulder arthroscopic surgery, might be explained by the underlying mechanisms of $\mathrm{CSH}$. In anesthesia related literature, there are two cases of asystolic cardiac arrest from $\mathrm{CSH}$, triggered by positioning for head and neck surgery $[26,27]$. Maggi et al. [28] suggested that cardiac pacing therapy has a beneficial effect on the neutrally mediated vasovagal syncope when the cardio-inhibitory $\mathrm{CSH}$ can predict an asystolic mechanism at the time of spontaneous syncope. Moreover, Heusser et al. [29] suggested recently that direct electric field stimulation of the carotid sinus baroreflex afferents acutely decreases arterial blood pressure in hypertensive patients, without negative effects on physiological baroreflex regulation. This depressor response is mediated predominantly through the inhibition of the sympathetic nervous system.

\section{Orthostatic syncope and associated autonomic disorders}

HBEs seem to be related to orthostatic syncope and associated autonomic disorders. In general, with age our ability to maintain hemodynamic homeostasis during position changes becomes less effective. This predisposes elderly patients to significant changes in blood pressure upon standing and orthostatic hypotension $(\mathrm{OH})$. The prevalence of $\mathrm{OH}$ varies according to the population being studied. A range between $5 \%$ and $60 \%$ has been reported with the lower rate in elderly individuals living in the community. $\mathrm{OH}$ is defined as a reduction of SBP of at least $20 \mathrm{mmHg}$ or diastolic blood pressure of at least $10 \mathrm{mmHg}$ within 3 minutes of standing
(Table 3). Generally, orthostatic syncope occurs when the autonomic sympathetic vasomotor system is incapacitated and fails to respond to the challenges imposed by the upright position causing hypotension (Table 4). These systems control the hemodynamic balance of blood volume, cardiac function and peripheral resistance to maintain organ perfusion during active (e.g., assuming the erect from the supine position) or passive (e.g., head-up tilt) postural changes. Normally, 30\% of the blood volume is intrathoracic during the supine position. With active or passive upright positions, approximately $500 \mathrm{cc}$ of volume pools into the pelvic and lower extremity circulatory system. This sudden pooling produces a transient hypotension that triggers the baroreceptors in the carotid body and the cardiopulmonary system to decrease their basal cardioinhibitory firing via the nucleus tractus solitarius of the medulla oblongata. As a result, a decrease in vagal tone and an increase in sympathetic flow ensue, leading to an increase in heart rate, peripheral vascular resistance, stroke volume and subsequently blood pressure to resume hemodynamic homeostasis. In addition, active position change, such as standing, causes muscular contraction in the pelvis and the lower extremities and leads to an increase in resistance, subsequently increasing preload. The renin-angiotensin system and vasopressin play a role in this hemodynamic homeostasis, especially in long-term maintenance (Fig. 3) [30]. Any disturbance in this model will predispose the individual to $\mathrm{OH}$.

Among secondary forms, alcohol, diabetes, and amyloidosis are common causes as well as volume depletion in which the autonomic nervous system is not itself unbalanced but is unable of maintaining adequate blood pressure due to reduced circulating volume. Orthostatic syncope might also occur due to the effects of many drugs, mainly in the elderly, such as vasodilators and nitroglycerin, $\beta$ - and $\alpha$-adrenergic

Table 3. Hemodynamic Response to Upright Position

\begin{tabular}{ccc}
\hline & Normal & $\begin{array}{c}\text { Classical vasovagal sycope or } \\
\text { carotid sinus hypersensitivity }\end{array}$ \\
\hline BP & $\downarrow / \rightarrow$ & $\downarrow \downarrow$ \\
HR & $\downarrow / \rightarrow$ & $\downarrow$ \\
associatied autonomic disorder & $\downarrow$ \\
\hline
\end{tabular}

BP: blood pressure, HR: heart rate.

Table 4. Perioperative Factors Linked with Increased Risk of Orthostatic Hypotension

\begin{tabular}{lll}
\hline Physical and behavioural factors & Biochemical and humoral factors & \multicolumn{2}{c}{ Cardiovascular factors } \\
\hline Age & Electrolyte imbalance & Fasting status \\
Low body mass index & Changes in RAS & Supine elevated BP \\
Smoking & Blood loss during operation & Increase vascular stiffness \\
Prolonged bed rest & & Decreased baroreceptor sensitivity \\
Anxiety & & \\
\hline
\end{tabular}

RAS: renin-angiotensin system, BP: blood pressure, IV: intravenous. 
Sitting

$400-800$ cc (30\% of blood volume) drop from chest to pelvis and legs

$\mathrm{BP} \downarrow$

( $\downarrow 40 \%$ of stroke volume)
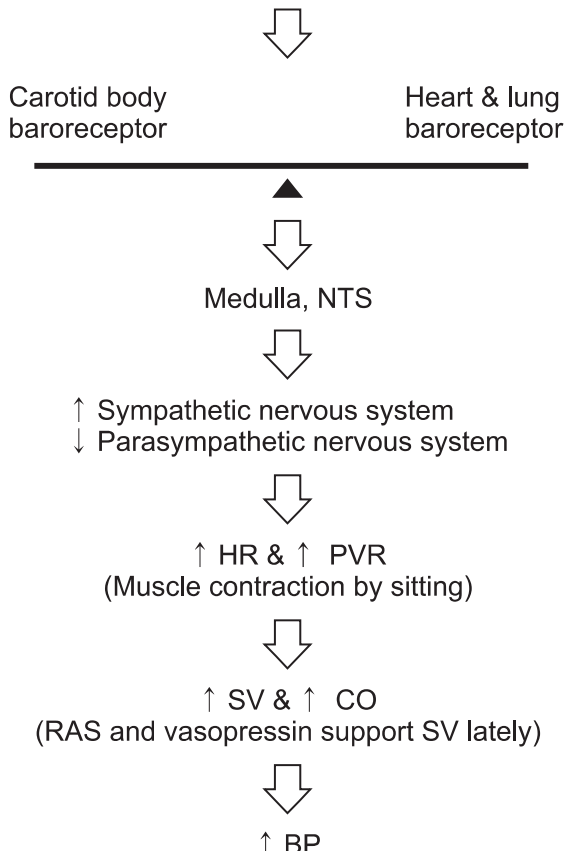

Fig. 3. This shows that renin angiotensin system (RAS) and vasopressin contribute the hemodynamic homeostasis in normal physiologic mechanism during upright position. BP: blood pressure, CO: cardiac output, HR: heart rate, NTS: nucleus tractus solitarius, PVR: peripheral vascular resistance, SV: stroke volume.

blockers, diuretics, anti-depressives, phenothiazines. In fact, because shoulder arthroscopic surgery is performed in a sitting position, it is true that there is a unique physiological change due to positional change. It is thought that preoperative NPO time or intraoperative bleeding may reduce circulating volume. ISBPB itself can affect autonomic influence by blocking the sympathetic chain. A stressful environment or a painful situation may also affect the activation of the sympathetic system. In addition, anesthesiologists frequently use antihypertensives or vasodilators in the management of high blood pressure during shoulder procedures. These factors can be associated with the occurrence of $\mathrm{OH}$-like events during shoulder surgery. Although antihypertensive medications as a group are thought to be major contributors to the increased risk of $\mathrm{OH}$, studies to document an association are conflicting. However, Sia et al. [8] reported that the incidence of HBEs during shoulder surgery were more frequent in the 24 patients who received antihypertensive medication (urapidil) compared to the 86 who did not $(37 \%$ versus $15 \%$; $\mathrm{P}<0.01)$. These observations indicate that one of the underlying causes for HBEs during shoulder surgery may be associated with the causes of $\mathrm{OH}$, especially intravenous bolus administration of antihypertensives during shoulder surgery.

\section{Realtionships between HBEs and the Bezold- Jarisch Reflex}

D'Alessio et al. [7] suggested that one proposed mechanism for the occurrence of HBEs is based on the activation of the Bezold-Jarisch reflex $[7,20]$. The Bezold-Jarisch reflex is an inhibitory reflex usually denoted as a cardioinhibitory reflex. Animal experiments have shown that the Bezold-Jarisch reflex has its origin in cardiac receptors with nonmyelinated type $\mathrm{C}$ vagal fibers constituting the afferent limb of the reflex [31]. Activation of the Bezold-Jarisch reflex initiates from an empty hypercontractile ventricle, which causes stimulation of intramyocardial mechanoreceptors (C fibers) and produces an abrupt withdrawal of sympathetic outflow, increasing vagal tone and thus causing bradycardia and hypotension. D'Alessio et al. [7] reported that the mechanism of the Bezold-Jarisch reflex during shoulder arthroscopic surgery was thought to be due to venous blood pooling (induced by the sitting position) and a heightened cardiac contractile state (induced by the $\beta$-adrenergic effects of epinephrine or isoproterenol), which result in reflex arterial vasodilation (mediated by activation of the parasympathetic nervous system) and a subsequent vagally mediated bradycardia. Further studies supported these hypotheses. Sia et al. [8] previously reported on a group of patients who received exogenous epinephrine $(200 \pm 13 \mu \mathrm{g})$ and in whom the incidence of HBEs was significantly higher than that in a group of patients who did not $(29 \%$ versus $11 \%$; $\mathrm{P}$ $=0.018$ ). The authors suggested that even a small epinephrine dose, such as that administered with the local anesthetic mixture for ISBPB, can result in a blood level that is high enough in some patients to initiate the Bezold-Jarisch reflex when associated with the placement of the patient in the sitting position. However, Seo et al. [10] reported that the number of patients who received local anesthetics with epinephrine (150 $\mu \mathrm{g})$, for ISBPB, were not significantly different between the HBEs and non-HBEs groups. In fact, there is no direct evidence for increased contractility due to epinephrine used in local anesthetic mixtures for nerve blocks [32]. In regard to the role of epinephrine in HBEs, the available studies are sparse and cross sectional, and there are multiple factors that can explain the lack of consistency between the various published studies. Hence, it is difficult to conclude causality.

Based on the concept of the hypercontractile left ventricle to initiate the Bezold-Jarisch reflex, Liguori et al. [9] investigated the prophylactic effect of the $\beta$-blocker on the occurrence of HBEs. They suggested that a $\beta$-blocker markedly decreases the 
incidence of HBEs when given prophylactically immediately after the administration of the interscalene block. On the contrary, Kahn and Hargett [15] reported that there was a $13 \%$ incidence of HBEs that were not affected by the use of $\beta$-blockers. These controversies indicate that the prophylactic effect of $\beta$-blockers on HBEs is still unclear.

In regard to the relationship between HBEs and the BezoldJarisch reflex, up to now, there is no convincing clinical data in the literature to support prerequisites (central volume depletion and hypercontractile empty ventricle) for the activation of the Bezold-Jarisch reflex. Some experiments using echocardiography also fail to demonstrate either an empty ventricle or a more vigorous contraction, as measured by endsystolic length or fractional systolic shortening, during syncopal episodes [33,34]. In addition, cardiac transplant patients have had classic vasovagal syncope, even though there is no clear evidence for reinnervation of the transplanted heart [35]. Campagna and Carter [36] noted that vasovagal syncope is not synonymous with the Bezold-Jarisch reflex nor is it necessarily dependent upon cardio-inhibitory receptor activation or the formal Bezold-Jarisch reflex. They suggested that the trigger factors for vasovagal syncope may be central, from psychic stress or pain, or may be initiated peripherally by a reduction in venous return to the heart. They also suggested that HBEs observed in shoulder surgery during ISB appear not to be related to the activation of Bezold-Jarisch reflex.

\section{New Contributing Factors for HBEs}

\section{Relationships between HBEs and SGB in the sitting position}

HBEs during shoulder surgery in the sitting position can be associated with SGB because it is not an infrequent complication of ISBPB. In fact, the incidence of SGB with Winnie's technique of ISBPB approaches 75\% [4]. In addition, cardiac sympathetic fibers originate from the stellate ganglia in conjunction with the superior and middle cervical ganglia and the first 4 or 5 thoracic sympathetic ganglia [37]. Hence, SGB after an ISBPB may affect cardiac sympathetic function. SGB itself is a common procedure for pain management. Patients in the pain clinic center occasionally experience dizziness, likely because of orthostatic hypotension, when standing after SGB. This episode of dizziness looks very similar to the occurrence of HBEs, when sitting after ISBPB. The symptoms after SGB may well be caused by impaired compensatory baroreflex integrity because SGB affects not only cardiac sympathetic nerves but also vagal afferents, including aortic depressor nerves, and these nerves play important roles in the baroreflex mechanism [38]. Interestingly, the effects of right and left SGB on heart rate and systolic blood pressure are different because of hemi-lateralization in the autonomic cardiovascular control. There is sympathetic predominance in the right hemisphere and parasympathetic predominance in the left hemisphere $[39,40]$. Taneyama and Goto [41] demonstrated that right SGB affected both heart rate and systolic blood pressure variability, but left SGB affected only systolic blood pressure and not heart rate variability. There is some evidence supporting these observations that stellectomy of the right-side ganglion diminished the increase in heart rate during exercise in dogs [42], whereas pharmacological right-sided SGB may attenuate not only sympathetic but also parasympathetic activity in humans [43]. In regard to HBEs, Seo et al. [10] demonstrated that 12 of 13 patients (92.3\%) who had HBEs received a right side ISBPB, suggesting that the site of ISBPB may be a contributing factor to the occurrence of HBEs. They suggested that a predominance of right-sided blocks in HBEs may be associated with right SGB as a complication of ISBPB. Although D'Alessio et al. [7] did not find a predominance of right-sided blocks in HBEs, several reports and cases are supporting these hypotheses. Rogers et al. [39] demonstrated a significantly slowed heart rate after right SGB but not after a left-sided block. Fujii et al. [44] reported that right SGB induces significant increases in the QT interval and rate-corrected QT (QTc) interval for 50 minutes after the block, but left SGB induces a significant decrease in the QT interval and the QTc interval. They suggested that autonomic innervation to the sinus node is mainly through the right-sided stellate ganglion. Nakagawa et al. [45] reported that a $70^{\circ}$ head-up tilt produced significant increases in the QT interval and QTc dispersion because the head-up tilt increased sympathetic tone and/or decreased vagal tone. Masuda and Fujiki [46] reported a case of sinus arrest that occurred after a head-up tilt in right SGB, most likely because of a vasovagal reflex. These observations indicate that right SGB, as a complication of ISBPB, may be associated with increased risks of HBEs during a shoulder procedure in the sitting position. However, Koyama et al. [47] suggested that right SGB, during the head up tilt test, suppresses cardiac sympathetic function without significantly affecting blood pressure and thus may be a safe and effective therapy for the chronic pain syndrome. In addition, up to now, there is a lack of clinical evidence that the right SGB after ISBPB in the sitting position is related to the cause of HBEs during shoulder surgery. As such, a prospective and randomized study is needed in the future to confirm whether right side ISBPB is a risk factor for HBEs.

\section{HBEs and sedatives or analgesics}

The limbic system is concerned with emotions, and in some animal species stimulation of the limbic sympatho-inhibitory 
center causes hypotension and bradycardia [48]. Although episodes of bradycardia may occur during regional anesthesia in the absence of sedation, oversedation may increase the risk. Hypnotic drugs should be given to obtain anxiolysis, rather than deep sedation [20]. In addition, there is some evidence that endogenous opioids, which are important neurotransmitters in the nucleus tractus solitarius, are involved in syncopal reactions in animals [49]. Griffioen et al. [50] demonstrated that fentanyl inhibits GABAergic transmission to cardiac vagal neurons in the nucleus ambiguus, providing one mechanism for opioidinduced bradycardia.

It is not well known whether intravenous administration of sedatives would be a triggering factor for the occurrence of HBEs during shoulder surgery. Previous studies have suggested that intraoperative sedation is not a major triggering factor for HBEs [8,9]. Souron et al. [51] demonstrated that in a single observation group, with 140 patients, target-controlled propofol infusion $(0.8-0.9 \mu \mathrm{g} / \mathrm{ml})$ following hydroxyzine premedication is a safe and effective technique for sedation when combined with ISBPB during shoulder surgery in the sitting position. The incidence of HBEs in their study was 5.7\% (8 patients). With supplementation during regional anesthesia, an intravenous bolus of fentanyl $(1-3 \mu \mathrm{g} / \mathrm{kg})$ is frequently chosen because of its potent, short-lasting analgesia. However, Seo et al. [10] demonstrated that there is a higher incidence of fentanyl supplementation in the HBEs group (53.8\%) compared to the non-HBEs group (4\%). In addition, Song et al. [52] demonstrated that the incidence of HBEs is increased in the group receiving an intravenous bolus administration with 100 mcg of fentanyl (27.5\%) compared with the saline group (10\%). Although $100 \mu \mathrm{g}$ of fentanyl is a reasonable dose, it can produce a marked decrease in arterial blood pressure, with a mean percent of change of approximately $20 \%$. This finding suggests that intravenous administration of fentanyl for incomplete ISBPB is a triggering factor for the occurrence of HBEs during shoulder arthroscopic surgery. Therefore, it is reasonable that the effective dose of fentanyl must be reduced by $50 \%$.

\section{HBEs and technical aspects of ISBPB}

To prevent major complications related with ISBPB, including HBEs, anesthesiologist should consider the technical aspects of ISBPB. First, anatomical structures related with major complications are located on the medial side from anterior scalene muscles. Therefore, a medially directed needle could increase the possibility of complications such as intravascular injections (the internal jugular vein or even the carotid artery), phrenic nerve block, epidural and spinal anesthesia, Horner's syndrome, hoarseness, and dysphagia. The symptoms from these complications might be associated with psychological factors to the vasovagal reflex reaction. Feigl et al. [53] demonstrated in their cadaveric study that the group of interscalene blocks by the Winnie technique, with the use of $30 \mathrm{ml}$, showed spread in a lateral direction in all cases and the dye additionally distributed medial to the anterior scalene and disseminated ventrally and dorsally to the anterior scalene muscle. It reached the phrenic nerve, the vagus nerve, the sympathetic trunk, and the great vessels of the superior mediastinum. In contrast, when they developed and used the supraomohyoidal block, which is an approach that avoids medially directed needle advancement and favors spread to lateral regions only, the phrenic nerve, stellate ganglion, laryngeal nerve and the vertebral artery were not exposed to the injected solution. Second, major complications of ISBPB often occur when the needle insertion is deeper than required because the interscalene block is a relatively "superficial" block. Third, the volume of local anesthetic for ISBPB should be considered to prevent the complications. Recent reports have suggested that ultrasonography-guided ISBPB can reduce the minimal effective volume of ISBPB [54], although it is unknown whether lower volumes of ISBPB can reduce the incidence of HBEs during shoulder surgery or not.

\section{Prevention and Treatment of HBEs}

Anesthesiologists should be concerned about whether patients have a history of syncopal episodes. A detailed history may provide a pattern to the attacks, precipitating factors, the severity and any previous medical investigations. In severe cases, cardiologic or neurologic investigation may be appropriate, such as Holter monitoring, head-up tilt-table testing, prolonged ECG monitoring and an electrophysiological study. Because vasovagal syncope does not occur in general anesthesia, the anesthetic choice of ISBPB for the patient with a syncopal history may not be appropriate. Drugs implicated in the genesis of asystole include propofol, fentanyl, suxamethonium and vecuronium [20]. In the patient without a history of syncope, preoperative appropriate hydration or an intraoperative stocking device [55] may be helpful to prevent HBEs. However, it is still unclear as to whether sedation could prevent HBEs or not. A small epinephrine dose administered with the local anesthetic mixture for ISBPB is not recommended, although there is no sufficient evidence for the relationship between exogenous epinephrine and HBEs. $\beta$-blockers have been suggested to decrease loss of consciousness susceptibility by diminishing the impact of the adrenergic surge and ventricular mechanoreceptor activation that commonly precedes and might trigger the reflex syncope [56,57]. There is some evidence that supports this hypothesis that is derived mainly from observational experiences and one small 
randomized trial [58,59]. However, a large randomized placebocontrolled double-blind trial showed no clear $\beta$-blocker benefit in terms of syncope recurrence prevention [60]. Selective serotonin reuptake inhibitors (SSRIs) have been thought to blunt an abnormal hypersensitive serotonin response in the central nervous system contributing to triggering neurally mediated syncope. However, clinical studies with SSRIs are still controversial. Paroxetine was shown to reduce syncope recurrence in 30 patients taking active medication compared with a placebo. Another study demonstrated no benefit in preventing the vasovagal reaction associated with carotid sinus massage and/or lower body negative pressure in healthy volunteers [61]. If there is a sudden, profound hemodynamic change after positional change or during the shoulder procedure in the sitting position, immediate $\alpha$-agonist vasoconstrictors are recommended in patients with orthostatic hypotension and recurrent vasovagal syncope [22]. In addition, Ephedrine is the drug of choice to treat the unknown origin of HBEs [20]. It constricts both arterial and venous capillary beds, thus increasing peripheral blood pressure, improving venous return and diminishing venous pooling.

\section{Conclusion}

Among the complications related to ISBPB, HBEs is still one of the major concerns to anesthesiologist. However, we believe that a better understanding of the mechanisms of HBEs can be a promising solution to reduce the incidence of HBEs during shoulder surgery under ISBPB. The basic mechanisms of HBEs may be associated with the underlying mechanisms responsible for vasovagal syncope, $\mathrm{CSH}$ or orthostatic syncope. Therefore, anesthesiologists have to know the pathophysiology and causes of these types of syncopal reactions. HBEs are observed in only awake conditions under isolated ISBPB. Many triggering stimuli act as afferent neural signals in the vasovagal reflex arc in the patient undergoing shoulder surgery. In regard to the relationships between HBEs and $\mathrm{CSH}$, it is a reasonable hypothesis that ISBPB or shoulder surgery in the sitting position can produce the prerequisite condition for the development of $\mathrm{CSH}$, such as blocking of SCM muscle movement or direct manipulation of the carotid sinus. In addition, HBEs may be related to $\mathrm{OH}$ because of its blocking properties of the sympathetic chain. $\mathrm{OH}$ is basically associated with the dysfunction of the autonomic nervous system. Intraoperative medication such as antihypertensives or fentanyl may be an important factor for the occurrence of $\mathrm{HBEs}$ or $\mathrm{OH}$. Moreover, it should be noted that SGB and a head-up tilt can be associated with increased risks of ventricular arrhythmias and cardiovascular diseases. These hypotheses and assumptions should be clarified with further clinical and experimental studies in the future. In regard to prevention of HBEs, recent reports have suggested that ultrasonography-guided ISBPB can reduce the minimal effective volume of ISBPB [54]. Therefore, future studies with ultrasonography-guided ISBPB will be promising in reducing the incidence of HBEs.

\section{References}

1. Skyhar MJ, Altchek DW, Warren RF, Wickiewicz TL, O'Brien SJ. Shoulder arthroscopy with the patient in the beach-chair position. Arthroscopy 1988; 4: 256-9.

2. Peruto CM, Ciccotti MG, Cohen SB. Shoulder arthroscopy positioning: lateral decubitus versus beach chair. Arthroscopy 2009; 25: 891-6.

3. Bishop JY, Sprague M, Gelber J, Krol M, Rosenblatt MA, Gladstone J, et al. Interscalene regional anesthesia for shoulder surgery. J Bone Joint Surg Am 2005; 87: 974-9.

4. Brull R, McCartney CJL, Sawyer RJ, von Schroeder HP. The indications and applications of interscalene brachial plexus block for surgery about the shoulder. Acute Pain 2004; 6: 57-77.

5. Fredrickson MJ, Ball CM, Dalgleish AJ. Analgesic effectiveness of a continuous versus single-injection interscalene block for minor arthroscopic shoulder surgery. Reg Anesth Pain Med 2010; 35: 28 33.

6. Gelber PE, Reina F, Caceres E, Monllau JC. A comparison of risk between the lateral decubitus and the beach-chair position when establishing an anteroinferior shoulder portal: a cadaveric study. Arthroscopy 2007; 23: 522-8.

7. D'Alessio JG, Weller RS, Rosenblum M. Activation of the bezoldjarisch reflex in the sitting position for shoulder arthroscopy using interscalene block. Anesth Analg 1995; 80: 1158-62.

8. Sia S, Sarro F, Lepri A, Bartoli M. The effect of exogenous epinephrine on the incidence of hypotensive/bradycardic events during shoulder surgery in the sitting position during interscalene block. Anesth Analg 2003; 97: 583-8.

9. Liguori GA, Kahn RL, Gordon J, Gordon MA, Urban MK. The use of metoprolol and glycopyrrolate to prevent hypotensive/bradycardic events during shoulder arthroscopy in the sitting position under interscalene block. Anesth Analg 1998; 87: 1320-5.

10. Seo KC, Park JS, Roh WS. Factors contributing to episodes of bradycardia hypotension during shoulder arthroscopic surgery in the sitting position after interscalene block. Korean J Anesthesiol 2010; 58: 38-44.

11. Ward ME. The interscalene approach to the brachial plexus. Anaesthesia 1974; 29: 147-57.

12. Wildsmith JA, Tucker GT, Cooper S, Scott DB, Covino BG. Plasma concentrations of local anaesthetics after interscalene brachial plexus block. Br J Anaesth 1977; 49: 461-6.

13. Vester-Andersen T, Christiansen C, Hansen A, Sorensen M, Meisler C. Interscalene brachial plexus block: area of analgesia, complications and blood concentrations of local anesthestics. Acta Anaesthesiol Scand 1981; 25: 81-4.

14. D'Alessio JG, Rosenblum M, Shea KP, Freitas DG. A retrospective comparison of interscalene block and general anesthesia for ambulatory surgery shoulder arthroscopy. Reg Anesth 1995; 20: 62- 
8.

15. Kahn RL, Hargett MJ. Beta-adrenergic blockers and vasovagal episodes during shoulder surgery in the sitting position under interscalene block. Anesth Analg 1999; 88: 378-81.

16. Turker G, Demirag B, Ozturk C, Uckunkaya N. Cardiac arrest after interscalene brachial plexus block in the sitting position for shoulder arthroscopy: a case report. Acta Orthop Belg 2004; 70: 846.

17. Brignole M, Menozzi C, Del Rosso A, Costa S, Gaggioli G, Bottoni N, et al. New classification of haemodynamics of vasovagal syncope: beyond the VASIS classification. Analysis of the pre-syncopal phase of the tilt test without and with nitroglycerin challenge. Vasovagal Syncope International Study. Europace 2000; 2: 66-76.

18. Brignole M, Menozzi C, Bottoni N, Gianfranchi L, Lolli G, Oddone D, et al. Mechanisms of syncope caused by transient bradycardia and the diagnostic value of electrophysiologic testing and cardiovascular reflexivity maneuvers. Am J Cardiol 1995; 76: 273-8.

19. Benditt DG, Fabian W, Iskos D, Lurie KG. Review article: heart rate and blood pressure control in vasovagal syncope. J Interv Card Electrophysiol 1998; 2: 25-32.

20. Kinsella SM, Tuckey JP. Perioperative bradycardia and asystole: relationship to vasovagal syncope and the bezold-jarisch reflex. $\mathrm{Br} \mathrm{J}$ Anaesth 2001; 86: 859-68.

21. Brignole M, Alboni P, Benditt DG, Bergfeldt L, Blanc JJ, Bloch Thomsen PE, et al. Guidelines on management (diagnosis and treatment) of syncope--update 2004. Europace 2004; 6: 467-537.

22. Task Force for the Diagnosis and Management of Syncope, European Society of Cardiology (ESC), European Heart Rhythm Association (EHRA), Heart Failure Association (HFA), Heart Rhythm Society (HRS), Moya A, Sutton R, et al. Guidelines for the diagnosis and management of syncope (version 2009). Eur Heart J 2009; 30: 2631-71.

23. Tea SH, Mansourati J, L'Heveder G, Mabin D, Blanc JJ. New insights into the pathophysiology of carotid sinus syndrome. Circulation 1996; 93: 1411-6.

24. Kirchheim HR. Systemic arterial baroreceptor reflexes. Physiol Rev 1976; 56: 100-77.

25. Querry RG, Smith SA, Stromstad M, Ide K, Secher NH, Raven $\mathrm{PB}$. Anatomical and functional characteristics of carotid sinus stimulation in humans. Am J Physiol Heart Circ Physiol 2001; 280: H2390-8.

26. Chung HS, Park CM, Kim ES, Ghil BG, Park CS. Temporary cardiac arrest in patient under robotically assisted total thyroidectomy causing carotid sinus hypersensitivity -A case report-. Korean J Anesthesiol 2010; 59 (Suppl): S137-40.

27. Truong AT, Sturgis EM, Rozner MA, Truong DT. Recurrent episodes of asystole from carotid sinus hypersensitivity triggered by positioning for head and neck surgery. Head Neck 2011; [Epub ahead of print]

28. Maggi R, Menozzi C, Brignole M, Podoleanu C, Iori M, Sutton R, et al. Cardioinhibitory carotid sinus hypersensitivity predicts an asystolic mechanism of spontaneous neurally mediated syncope. Europace 2007; 9: 563-7.

29. Heusser K, Tank J, Engeli S, Diedrich A, Menne J, Eckert S, et al. Carotid baroreceptor stimulation, sympathetic activity, baroreflex function, and blood pressure in hypertensive patients.
Hypertension 2010; 55: 619-26.

30. Hajjar I. Postural blood pressure changes and orthostatic hypotension in the elderly patient: impact of antihypertensive medications. Drugs Aging 2005; 22: 55-68.

31. Donald DE, Shepherd JT. Reflexes from the heart and lungs: physiological curiosities or important regulatory mechanisms. Cardiovasc Res 1978; 12: 446-69.

32. Bonica JJ, Akamatsu TJ, Berges PU, Morikawa K, Kennedy WF Jr. Circulatory effects of peridural block. II. Effects of epinephrine. Anesthesiology 1971; 34: 514-22.

33. Novak V, Honos G, Schondorf R. Is the heart 'empty' at syncope? J Auton Nerv Syst 1996; 60: 83-92.

34. Liu JE, Hahn RT, Stein KM, Markowitz SM, Okin PM, Devereux RB, et al. Left ventricular geometry and function preceding neurally mediated syncope. Circulation 2000; 101: 777-83.

35. Montebugnoli L, Montanari G. Vasovagal syncope in heart transplant patients during dental surgery. Oral Surg Oral Med Oral Pathol Oral Radiol Endod 1999; 87: 666-9.

36. Campagna JA, Carter C. Clinical relevance of the bezold-jarisch reflex. Anesthesiology 2003; 98: 1250-60.

37. Janes RD, Brandys JC, Hopkins DA, Johnstone DE, Murphy DA, Armour JA. Anatomy of human extrinsic cardiac nerves and ganglia. Am J Cardiol 1986; 57: 299-309.

38. Ikeda T, Iwase S, Sugiyama Y, Matsukawa T, Mano T, Doi M, et al. Stellate ganglion block is associated with increased tibial nerve muscle sympathetic activity in humans. Anesthesiology 1996; 84: 843-50.

39. Rogers MC, Battit G, McPeek B, Todd D. Lateralization of sympathetic control of the human sinus node: ECG changes of stellate ganglion block. Anesthesiology 1978; 48: 139-41.

40. Hilz MJ, Dutsch M, Perrine K, Nelson PK, Rauhut U, Devinsky O. Hemispheric influence on autonomic modulation and baroreflex sensitivity. Ann Neurol 2001; 49: 575-84.

41. Taneyama C, Goto H. Fractal cardiovascular dynamics and baroreflex sensitivity after stellate ganglion block. Anesth Analg 2009; 109: 1335-40.

42. Schwartz PJ, Stone HL. Effects of unilateral stellectomy upon cardiac performance during exercise in dogs. Circ Res 1979; 44: 63745.

43. Fujiki A, Masuda A, Inoue H. Effects of unilateral stellate ganglion block on the spectral characteristics of heart rate variability. Jpn Circ J 1999; 63: 854-8.

44. Fujii K, Yamaguchi S, Egawa H, Hamaguchi S, Kitajima T, Minami J. Effects of head-up tilt after stellate ganglion block on QT interval and QT dispersion. Reg Anesth Pain Med 2004; 29: 317-22.

45. Nakagawa M, Takahashi N, Iwao T, Yonemochi H, Ooie T, Hara M, et al. Evaluation of autonomic influences on QT dispersion using the head-up tilt test in healthy subjects. Pacing Clin Electrophysiol 1999; 22: 1158-63.

46. Masuda A, Fujiki A. Sinus arrest after right stellate ganglion block. Anesth Analg 1994; 79: 607.

47. Koyama S, Sato N, Nagashima K, Aizawa H, Kawamura Y, Hasebe $\mathrm{N}$, et al. Effects of right stellate ganglion block on the autonomic nervous function of the heart: a study using the head-up tilt test. Circ J 2002; 66: 645-8.

48. van Lieshout JJ, Wieling W, Karemaker JM, Eckberg DL. The 
vasovagal response. Clin Sci (Lond) 1991; 81: 575-86.

49. Wallbridge DR, MacIntyre HE, Gray CE, Oldroyd KG, Rae AP, Cobbe SM. Role of endogenous opioids and catecholamines in vasovagal syncope. Eur Heart J 1996; 17: 1729-36.

50. Griffioen KJ, Venkatesan P, Huang ZG, Wang X, Bouairi E, Evans C, et al. Fentanyl inhibits GABAergic neurotransmission to cardiac vagal neurons in the nucleus ambiguus. Brain Res 2004; 1007: 10915 .

51. Souron V, Delaunay L, Bonner F. Sedation with target-controlled propofol infusion during shoulder surgery under interscalene brachial plexus block in the sitting position: report of a series of 140 patients. Eur J Anaesthesiol 2005; 22: 853-7.

52. Song SY, Son SH, Kim SO, Roh WS. Intravenous fentanyl during shoulder arthroscopic surgery in the sitting position after interscalene block increases the incidence of episodes of bradycardia hypotension. Korean J Anesthesiol 2011; 60: 344-50.

53. Feigl G, Fuchs A, Gries M, Hogan QH, Weninger B, Rosmarin W. A supraomohyoidal plexus block designed to avoid complications. Surg Radiol Anat 2006; 28: 403-8.

54. Conroy PH, Awad IT. Ultrasound-guided blocks for shoulder surgery. Curr Opin Anaesthesiol 2011; 24: 638-43.

55. Kwak HJ, Lee JS, Lee DC, Kim HS, Kim JY. The effect of a sequential compression device on hemodynamics in arthroscopic shoulder surgery using beach-chair position. Arthroscopy 2010; 26: 729-33.

56. Grubb BP. Clinical practice. neurocardiogenic syncope. N Engl J Med 2005; 352: 1004-10.

57. Lacroix D, Dubuc M, Kus T, Savard P, Shenasa M, Nadeau R. Evaluation of arrhythmic causes of syncope: correlation between holter monitoring, electrophysiologic testing, and body surface potential mapping. Am Heart J 1991; 122: 1346-54.

58. Mahanonda N, Bhuripanyo K, Kangkagate C, Wansanit K, Kulchot B, Nademanee K, et al. Randomized double-blind, placebo-controlled trial of oral atenolol in patients with unexplained syncope and positive upright tilt table test results. Am Heart J 1995; 130: 1250-3.

59. Nair N, Padder FA, Kutalek SP, Kantharia BK. Usefulness of pindolol for treatment of neurocardiogenic syncope. Am J Cardiol 2004; 94: 1189-91.

60. Sheldon R, Connolly S, Rose S, Klingenheben T, Krahn A, Morillo C, et al. Prevention of syncope trial (POST): a randomized, placebocontrolled study of metoprolol in the prevention of vasovagal syncope. Circulation 2006; 113: 1164-70.

61. Takata TS, Wasmund SL, Smith ML, Li JM, Joglar JA, Banks K, et al. Serotonin reuptake inhibitor (Paxil) does not prevent the vasovagal reaction associated with carotid sinus massage and/or lower body negative pressure in healthy volunteers. Circulation 2002; 106: $1500-4$. 